Article

\title{
Reduction Behavior of Chromium (VI) with Oxalic Acid in
}

\section{Aqueous Solution}

\author{
Hao Peng *1, Jing Guo, Binfang Yuan, Liping Lv, Huisheng Huang, Bing Li \\ College of Chemistry and Chemical Engineering, Yangtze Normal University, Chongqing 408100, China;

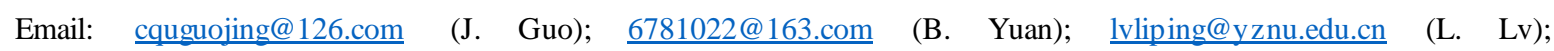 \\ h.s.huang@hotmail.com (H. Huang); 1127753494@qq.com (B. Li)
}

* Correspondence: cqupenghao@126.com (H. Peng), Tel.: +86 15123031643 (H. Peng),

\begin{abstract}
The direct $\mathrm{Cr}(\mathrm{VI})$ reduction process by oxalic acid was conducted and the results showed that the $\mathrm{Cr}(\mathrm{VI})$ was efficiently reduced by oxalic acid at high reaction temperature and high dosage of oxalic acid. The reduced product, $\mathrm{Cr}$ (III), w as easily generated stable complex compounds $(\mathrm{Cr}(\mathrm{HC} 2 \mathrm{O} 4) 3)$ with oxalate, which displayed a negative effect on the reduction process. The high reaction temperature and high acidic medium could destroy the stable structure of a complex compound to release oxalate, and facilitate the reduction of $\mathrm{Cr}(\mathrm{VI})$. Generally, the present study provided a versatile strategy for $\mathrm{Cr}$ (VI) reduction, exhibiting a bright application future for real wastewater treatment.
\end{abstract}

Keywords: Chromium; Reduction; Oxalic Acid

\section{Introduction}

Chromium (VI), placed in the fourth period of the periodic table [1-3], was a toxicity heavy metal ion and is classified in Group 1 (carcinogenic to humans) by the International Agency for Research on Cancer $[4,5]$. It was harmful to the environment and human health and some treatments were needed.

Nowadays, many remediation techniques had been developed to remove chromium (VI) from wastewater. They were mainly divided into three kinds: physicochemical technology, electrochemical technology and advanced oxidation technology. Physicochemical technologies included membrane filtration, chemical precipitation, ion-exchange, and adsorption [6-8]. Electrocoagulation, electrochemical reduction, electrodialysis and electrode-ionization were belonged to electrochemical technology [9-11]. Photocatalysis and nanotechnology were advanced oxidation technology which was practical approaches in treating wastewaters $[12,13]$. A recent study found that lead sulfate as precipitation was used to precipitate chromium (VI) and it could remove Cr (VI) from $0.2 \mathrm{~mol} / \mathrm{L}$ to $0.15 \mathrm{mmol} / \mathrm{L}$ [14], but lead sulfate was a second pollutant which was harmful for the environment. At the same time, difficulties and challenges like high costs, large scale applications and causing secondary pollution still remained in current technologies. It needed to overcome these challenges and develop new effective techniques for the removal of $\mathrm{Cr}$ (VI). Consequently, disposal of $\mathrm{Cr}$ (VI)-contaminated wastewaters was a serious environmental concern, and its reduction to $\mathrm{Cr}$ (III) attracted significant attention.

Oxalic acid, mainly from the decomposition of organic matter and plant root exudates, was one of the most widely natural existed organic acids [15]. It was extensively applied to reduce Cr (VI) because of its environmentally friendly nature and low cost $[16,17]$. Mu found that in the direct $\mathrm{Cr}(\mathrm{VI})$ reduction process, the $\mathrm{Cr}(\mathrm{VI})$ concentration did not change obviously in the oxalic acid or $\mathrm{Mn} 2+$ aqueous solution. Interestingly, the addition of $\mathrm{Mn} 2+$ into the $\mathrm{Cr}(\mathrm{VI}) /$ oxalic acid system, $99 \% \mathrm{Cr}(\mathrm{VI})$ was reduced and they

1 Correspondence concerning this article should address to Hao Peng at cqupenghao@126.com 
concluded that Mn2+ could promote Cr (VI) reduction with oxalic acid [18]. Many methods had been proposed to speed up the $\mathrm{Cr}(\mathrm{VI})$ reduction by oxalic acid, like catalyzed by $\mathrm{TiO} 2, \mathrm{Al} 2 \mathrm{O} 3$ and $\mathrm{FeOOH}$ [19], but these oxalic acid-based methods were still not feasible for the practical application, especially in the case of groundwater remediation. The direct $\mathrm{Cr}$ (VI) reduction by oxalic acid was thermodynamically feasible [20], the reduction process and reaction mechanism were investigated in this paper.

\section{Materials and Methods}

\subsection{Materials}

Potassium dichromate (K2Cr2O7), sulfate acid (H2SO4), and oxalic acid ( $\mathrm{H} 2 \mathrm{C} 2 \mathrm{O} 4 \cdot 2 \mathrm{H} 2 \mathrm{O})$ were purchased from Kelong Co., Ltd, Chengdu, China. All chemicals were used as received without further purified. All solutions were prepared with deionized water with a resistivity greater than $18 \mathrm{M} \Omega / \mathrm{cm}$ (HMC-WS10).

\subsection{Experimental procedure}

All the experiments were carried out in a $250 \mathrm{~mL}$ beaker fixed in a thermostatic water bath with a temperature precision of $\pm 0.1{ }^{\circ} \mathrm{C}$. In the batch experiments, a volume of $100 \mathrm{~mL}$ solution contained 1000 $\mathrm{mg} / \mathrm{L} \mathrm{Cr}(\mathrm{VI})$ was prepared by dissolving analytical grade $\mathrm{K} 2 \mathrm{Cr} 2 \mathrm{O} 7$ in deionized water, then the oxalic acid was added into the solution as the solution heated to a predetermined temperature. During the experiments, the samples were collected at different intervals $(5 \mathrm{~min})$, and analyzed for residual concentration of $\mathrm{Cr}(\mathrm{VI})$ in the solution $[10,11,14]$.

The concentration of $\mathrm{Cr}(\mathrm{VI})$ in the solution was determined by inductive couple plasma-optical emission spectrometry (ICP-OES)[21]. And the reduction efficiency ( $\eta$ ) was calculated as Equation (1):

$$
\eta=\frac{C_{0}-C_{t}}{C_{0}} \times 100 \%
$$

Where, $\mathrm{C} 0$, is the initial concentration of $\mathrm{Cr}(\mathrm{VI})$ in the solution, $\mathrm{mg} / \mathrm{L} ; \mathrm{Ct}$, is the concentration of $\mathrm{Cr}$ (VI) in the solution at reaction time of $\mathrm{t}, \mathrm{mg} / \mathrm{L}$.

\section{Results and Discussion}

It was known that $\mathrm{E}^{0}\left(\mathrm{HCrO}_{4}{ }^{-} / \mathrm{Cr}^{3+}\right)=1.33 \mathrm{~V}$ and $\mathrm{E} 0\left(\mathrm{C}_{2} \mathrm{O}_{4}{ }^{2-} / \mathrm{CO}_{2}\right)=0.49 \mathrm{~V}$, and therefore $\mathrm{H}_{2} \mathrm{C}_{2} \mathrm{O}_{4}$ could be used as a reductant for $\mathrm{Cr}(\mathrm{VI})$ reduction. With a summarization of the potential-pH diagram of chromium and oxalic acid shown in Figure 1a, it was clear that the position of oxalic acid was always lower than $\mathrm{Cr}(\mathrm{VI})$, indicating that the electrode potential of oxalic acid was lower than oxalic acid. Therefore, oxalic acid could reduce $\mathrm{Cr}$ (VI) into $\mathrm{Cr}$ (III). The main reaction during the reduction process was between chromium and oxalic acid. The $\triangle \mathrm{G}$ of main reactions were calculated at $298 \mathrm{~K}^{[21-23]}$. The results displayed in Figure 1b showed that the $\triangle \mathrm{G}$ was negative, which indicated that the reduction of $\mathrm{Cr}(\mathrm{VI})$ with oxalic acid was feasible in thermodynamic. 

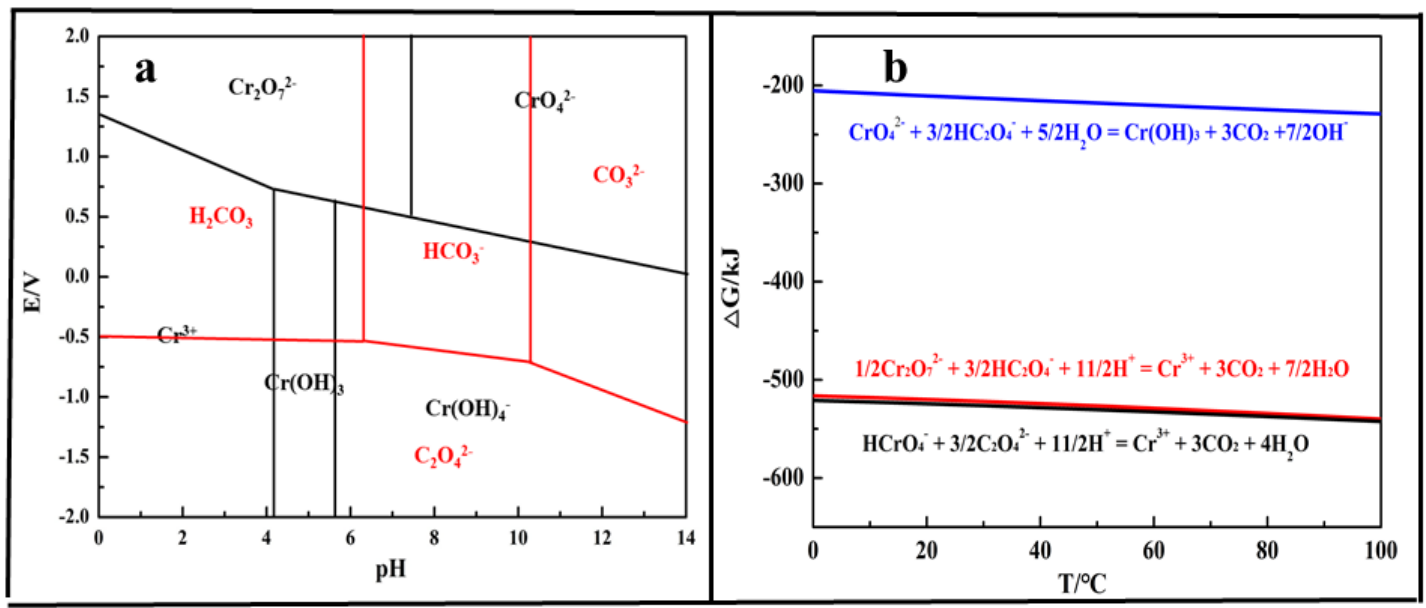

Figure 1 a) E-pH diagram of $\mathrm{Cr}(\mathrm{VI})$ and oxalic acid at $25^{\circ} \mathrm{C}$; b) Relationship between $\Delta \mathrm{G}$ and temperature of reduction of $\mathrm{Cr}(\mathrm{VI})$

\subsection{Reaction mechanism}

The existence of $\mathrm{Cr}(\mathrm{VI})$ in the reaction medium was measured by software Visual MINTEQ 3.0 and the result was showed in Figure 3a. During the $\mathrm{Cr}(\mathrm{VI})$ reduction process, the predominant $\mathrm{Cr}(\mathrm{VI})$ species was $\mathrm{HCrO}_{4}^{-}$and the reduction process was reacted following Equation (2) showed in Figure 2. The $\mathrm{Cr}$ (VI) was reduced to $\mathrm{Cr}^{3+}$ and $\mathrm{H}_{2} \mathrm{C}_{2} \mathrm{O}_{4}$ was oxidized to $\mathrm{CO}_{2}$. The reaction process could be divided into two parts: I) The formation of ester-like compounds between $\mathrm{HCrO}_{4}{ }^{-}$and $\mathrm{H}_{2} \mathrm{C}_{2} \mathrm{O}_{4}$ following Equation (3) showed in Figure 2. II) The electron migration between the inner of ester-like compounds following Equation (4) showed in Figure 2 [18].

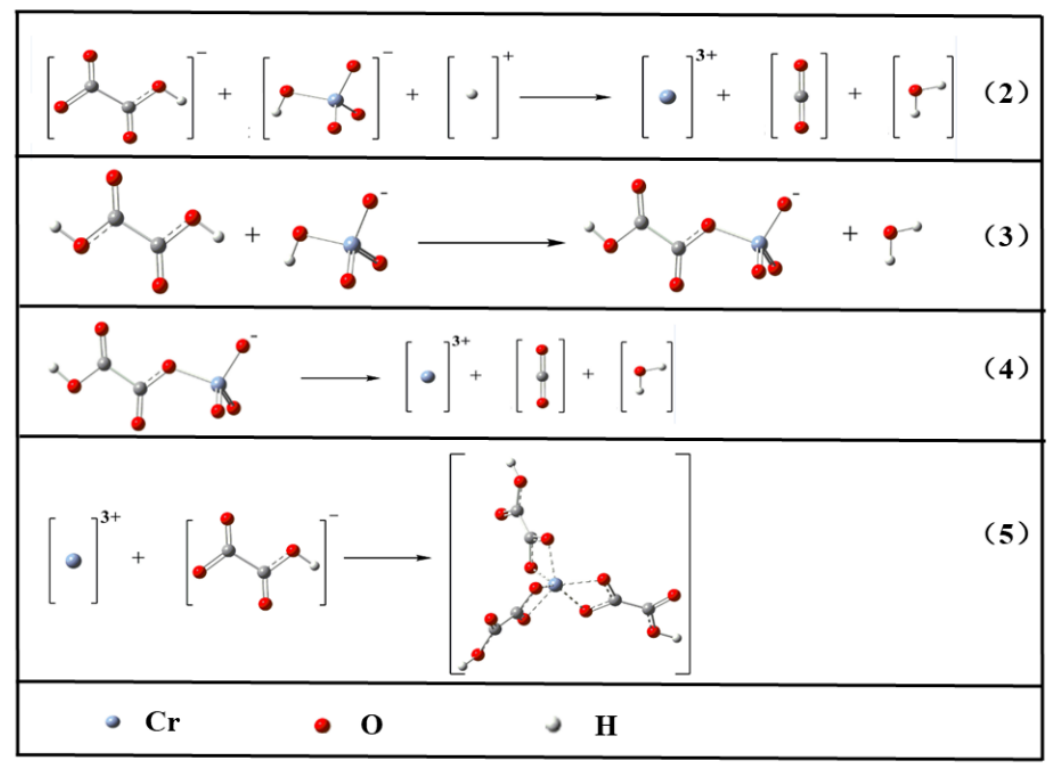

Figure 2 Reaction mechanism for reduction of Cr (VI) with oxalic acid

\subsection{Reduction process}

The dosage of oxalic acid played an important role during the reduction process as it was the main reaction reagent. A series of experiments were conducted to investigate the effect of the dosage of oxalic acid $(\mathrm{n}(\mathrm{O}) / \mathrm{n}(\mathrm{Cr}))$ on the reduction efficiency of $\mathrm{Cr}(\mathrm{VI})$ at reaction temperature of $70{ }^{\circ} \mathrm{C}$ with $500 \mathrm{rpm}$. 
The results were shown in Figure 3b indicated that reduction efficiency was increased with the increase of dosage of oxalic acid. The reduction efficiency was increased from $24.3 \%$ to $99.9 \%$ as dosage of oxalic acid increased from $n(O) / n(C r)=1.5$ to $n(O) / n(C r)=6.0$. At the beginning of the reduction process, the reduction efficiency of $\mathrm{Cr}(\mathrm{VI})$ was high due to the high concentration of $\mathrm{Cr}(\mathrm{VI})$ and oxalic acid and fast reaction rate. Along with the reduction process, the increasing trend of reduction efficiency of $\mathrm{Cr}(\mathrm{VI})$ became smooth due to the formation of a soluble $\mathrm{Cr}$ (III)-organic products, which formed by $\mathrm{Cr}^{3+}$ and oxalate (Equation (5) showed in Figure 2)[18]. In order to improve the reduction efficiency of $\mathrm{Cr}$ (VI), the high dosage of oxalic acid should be added as there was no enough oxalate to reduce $\mathrm{Cr}$ (VI) at a lower dosage of oxalic acid. Thus, the $\mathrm{n}(\mathrm{O}) / \mathrm{n}(\mathrm{Cr})=6.0 \mathrm{w}$ as chosen as an optimal condition in further experiments.

The effect of reaction temperature on reduction efficiency of $\mathrm{Cr}(\mathrm{VI})$ was studied under the standard conditions: initial concentration of $\mathrm{Cr}(\mathrm{VI})$ of $1000 \mathrm{mg} / \mathrm{L}, \mathrm{n}(\mathrm{O}) / \mathrm{n}(\mathrm{Cr})=6.0$, and stirring rate of $500 \mathrm{rpm}$. It could be seen from Figure 3c that the reduction efficiency of $\mathrm{Cr}$ (VI) could up to $100 \%$ at all reaction temperatures with enough reaction time, and it was easily achieved at a higher reaction temperature in low reaction time, which was partially consistent with a recent study. Increasing the reaction temperature could increase the activity of atoms and molecules, enforced the reaction intensity, and promoted the reactions, and thus, was beneficial for the reduction of $\mathrm{Cr}$ (VI) [10, 11, 24]. Meanwhile, high reaction temperature could destroy the stable complex compound and release oxalate, which facilitated the reduction of $\mathrm{Cr}(\mathrm{VI})$, thus, the reduction efficiency of $\mathrm{Cr}(\mathrm{VI})$ was increased with the increase of reaction temperature. Therefore, the reaction temperature of $70^{\circ} \mathrm{C}$ was chosen as an optimal condition for further experiments.

Figure 3d summarized the effect of stirring rate on the reduction efficiency of $\mathrm{Cr}(\mathrm{VI})$ at reaction temperature of $70{ }^{\circ} \mathrm{C}, \mathrm{n}(\mathrm{O}) / \mathrm{n}(\mathrm{Cr})=6.0$, and it showed that the reduction efficiency of $\mathrm{Cr}(\mathrm{VI})$ weas all the same as stirring rate ranged from $100 \mathrm{rpm}$ to $500 \mathrm{rpm}$.

The acid condition favored the reduction of $\mathrm{Cr}$ (VI) to $\mathrm{Cr}$ (III) by oxalic acid according to Equation (2). The $\mathrm{Cr}(\mathrm{VI})$ reduction by oxalic acid was investigated at concentration of $\mathrm{H}_{2} \mathrm{SO}_{4}$ ranged from $0 \mathrm{~g} / \mathrm{L}$ to $300 \mathrm{~g} / \mathrm{L}$ in this study. The results showed in Figure 4 indicated that the addition of $\mathrm{H}_{2} \mathrm{SO}_{4}$ could facilitate $\mathrm{Cr}(\mathrm{VI})$ reduction process. It was widely accepted that $\mathrm{pH}$-dependent $\mathrm{Cr}(\mathrm{VI})$ reduction was attributed to the speciation and redox potentials of $\mathrm{Cr}(\mathrm{VI})$ at different $\mathrm{pH}$ values. Theoretically, $\mathrm{HCrO}_{4}^{-}$was the predominant $\mathrm{Cr}(\mathrm{VI})$ species at $0.8<\mathrm{pH}<6.8$, and $\mathrm{CrO}_{4}{ }^{2-}$ w as major species at $\mathrm{pH}>6.8$ (Figure 3a), while $\mathrm{HCrO}_{4}^{-}$was easier to be reduced into $\mathrm{Cr}(\mathrm{III})$ than $\mathrm{CrO}_{4}{ }^{2-}$ as $\mathrm{HCrO}_{4}^{-}$was a much stronger oxidant $\left(\mathrm{E}^{0}\left(\mathrm{HCrO}_{4}{ }^{-} / \mathrm{Cr}^{3+}\right)=1.35 \mathrm{~V}, \mathrm{E}^{0}\left(\mathrm{CrO}_{4}{ }^{2-} / \mathrm{Cr}^{3+}\right)=0.56 \mathrm{~V}\right)$. In high acidic medium, the complex compound was not stable and released oxalate, oxalate, which facilitated the reduction of $\mathrm{Cr}(\mathrm{VI})$, thus, the reduction efficiency of $\mathrm{Cr}(\mathrm{VI})$ was increased with the addition of $\mathrm{H}_{2} \mathrm{SO}_{4}$. Other way, the addition of $\mathrm{H}_{2} \mathrm{SO}_{4}$ could improve the reduction efficiency of $\mathrm{Cr}(\mathrm{VI})$, the dosage of $\mathrm{H}_{2} \mathrm{SO}_{4}$ had no obvious effect on the reduction efficiency at a high dosage of oxalic acid as the oxalate was enough. 


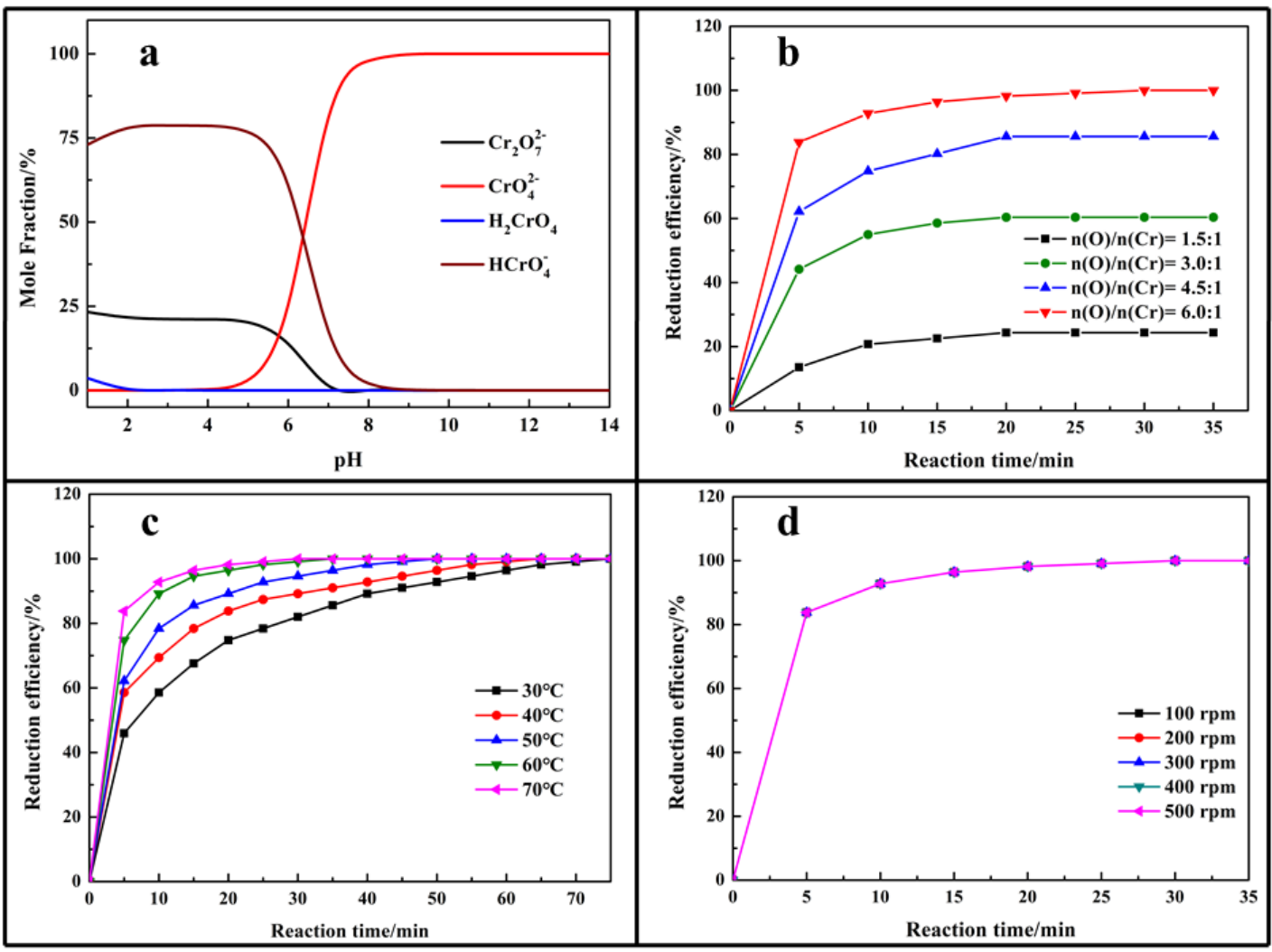

Figure 3 Effect of parameters on reduction efficiency of $\mathrm{Cr}(\mathrm{VI})$ a) mole fraction of $\mathrm{Cr}$ (VI) species at various $\mathrm{pH}$; b) dosage of oxalic acid; c) reaction temperature; d) stirring rate

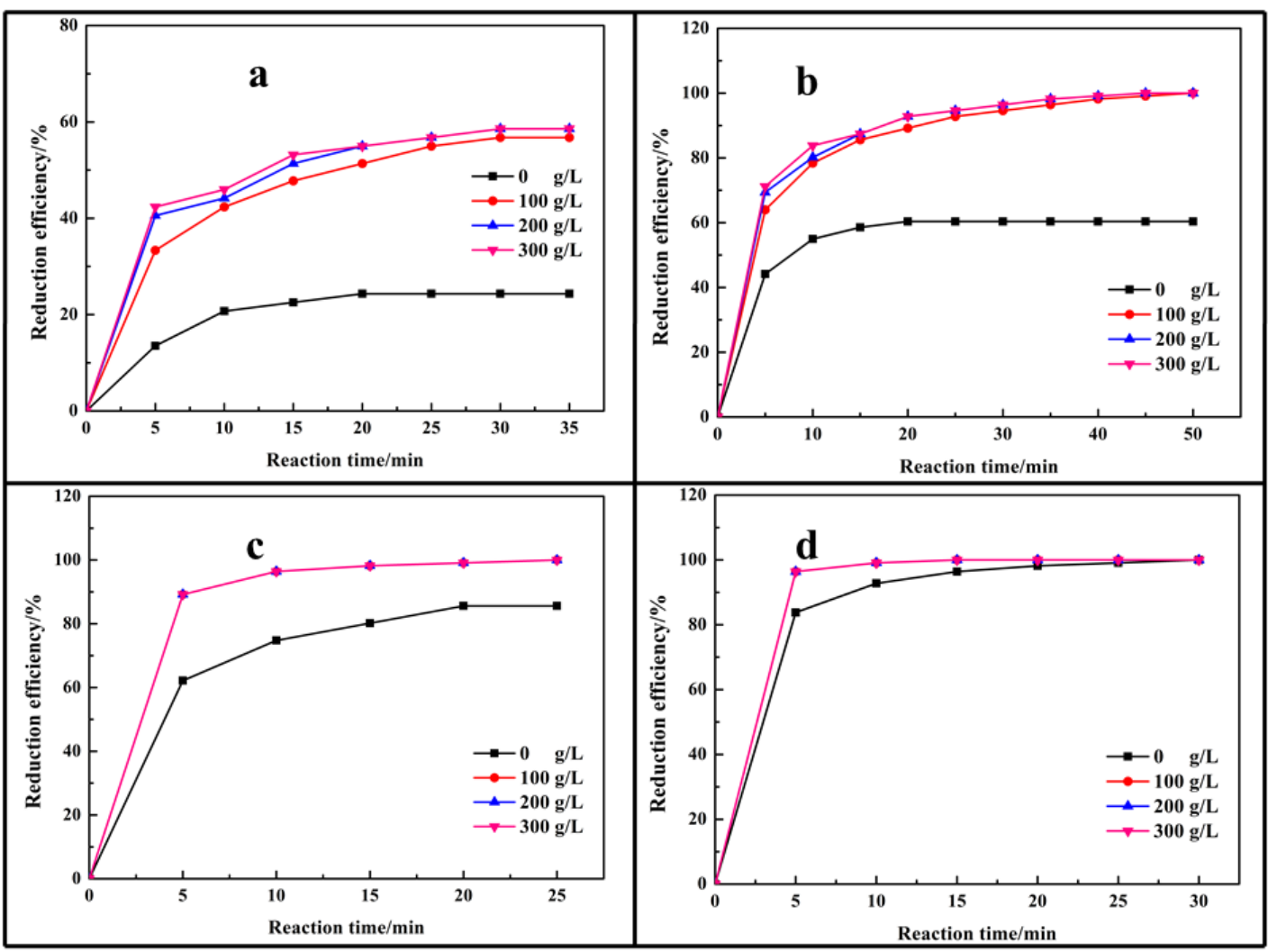


Figure 4 Effect of $\mathrm{H}_{2} \mathrm{SO}_{4}$ concentration on the reduction efficiency of $\mathrm{Cr}$ (VI) at various dosage of oxalic acid a)

$$
\mathrm{n}(\mathrm{O}) / \mathrm{n}(\mathrm{Cr})=1.5: 1 ; \mathrm{b}) \mathrm{n}(\mathrm{O}) / \mathrm{n}(\mathrm{Cr})=3.0: 1 ; \mathrm{c}) \mathrm{n}(\mathrm{O}) / \mathrm{n}(\mathrm{Cr})=4.5: 1 ; \mathrm{d}) \mathrm{n}(\mathrm{O}) / \mathrm{n}(\mathrm{Cr})=6.0: 1
$$

\subsection{Kinetics analysis}

The reduction of Cr (VI) could be expressed by pseudo-first-order equation as described as Equation (6) $[25-27]$.

$$
v=\frac{\mathbf{d C}}{\mathbf{d t}}=-\mathrm{K}_{\mathrm{obs}} \mathbf{C}
$$

Integrate.

$$
-\mathrm{LnC}=\mathrm{K}_{\mathrm{obs}} \mathrm{t}-\mathrm{LnC}_{\mathbf{0}}
$$

Where $v$ is the reduction rate of chromium (VI), $C$ is the concentration of $\mathrm{Cr}(\mathrm{VI}), C_{0}$ is the initial concentration of $\mathrm{Cr}(\mathrm{VI}), K_{o b s}$ is the reaction constant.

The experimental data were fitted as Equation (7) and the results were displayed in Figure 5a. The results showed in Figure 5a indicated that the data was fitted well as the coefficient $\left(R^{2}\right)$ all closely to 1 , which indic ated that the kinetic model was followed pseudo-first-order model equation. The relationship between $K_{o b s}$ and reaction temperature (T) could be expressed with the Arrhenius equation (Equation (8)) and the specific apparent activation energy could be calculated. The result showed in Figure 5b showed the simulated Arrhenius equation and the $E a$ was calculated as $22.49 \mathrm{KJ} / \mathrm{mol}$, which was much larger than the apparent energy calculated for electrochemic al reduction $(4.74 \mathrm{KJ} / \mathrm{mol})[10]$. It meant that the reduction process by oxalic acid was harder than electrochemical reduction, while the reduction efficiency $(100 \%)$ was much more efficient $(86.45 \%)$.

$$
\ln K_{o b s}=\ln \mathrm{A}-\mathbf{E a} / \mathbf{R T}
$$

Where $\mathrm{Ea}$ is the apparent activation energy, $\mathrm{A}$ is the pre-exponential factor, and $\mathrm{R}$ is the molar gas constant, $\mathrm{K}$ is the reduction rate constant at different reaction temperatures.

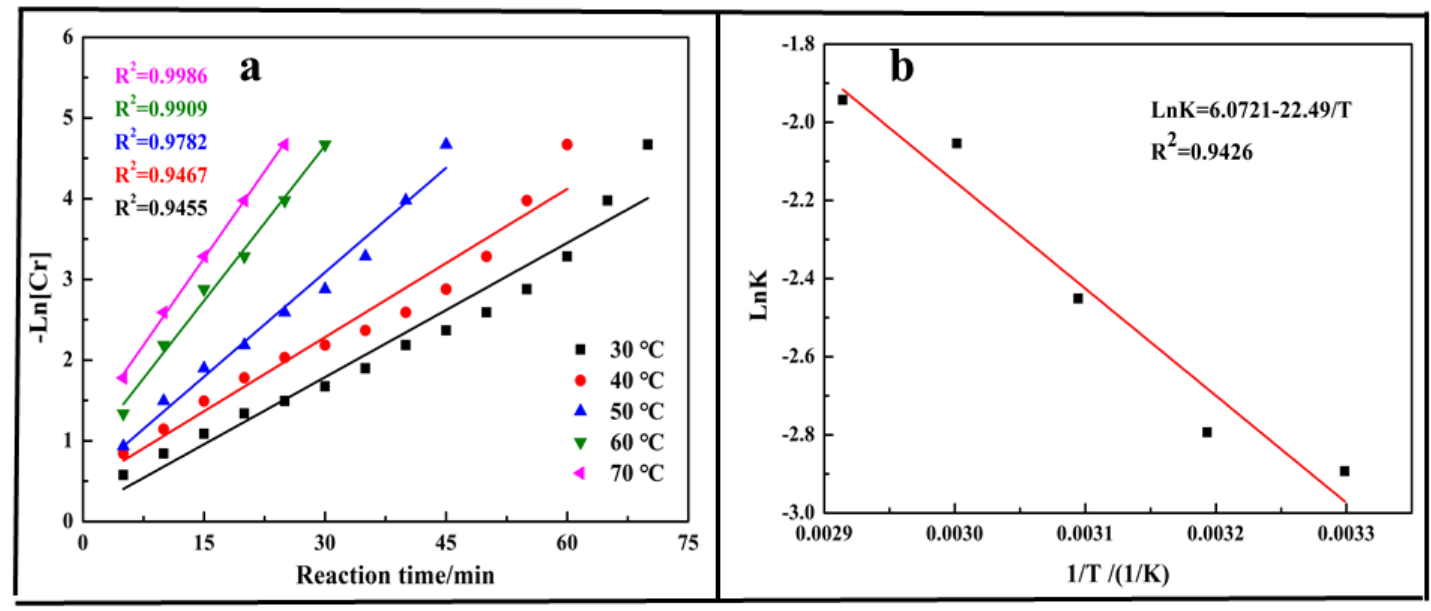

Figure 5 Kinetics plots: a) Plot of leaching kinetics of vanadium at various reaction temperatures; b) Natural logarithm of reaction rate constant versus reciprocal temperature

\section{Conclusions}


In this paper, the direct $\mathrm{Cr}(\mathrm{VI})$ reduction process by oxalic acid was conducted. The following conclusions could be obtained:

(1) $\mathrm{The} \mathrm{Cr}(\mathrm{VI})$ was easily reduced by oxalic acid at high reaction temperature and a high dosage of oxalic acid in acidic medium. Nearly $99.9 \%$ of $\mathrm{Cr}$ (VI) was reduced at $\mathrm{n}($ oxalic acid) $/ \mathrm{n}(\mathrm{Cr})=6.0$ and reaction temperature of $70^{\circ} \mathrm{C}$. The dosage of acid concentration and stirring rate had no obvious effect on $\mathrm{Cr}(\mathrm{VI})$ reduction process.

(2) The reduced product, $\mathrm{Cr}$ (III), was easily generated stable complex compounds $\left(\mathrm{Cr}\left(\mathrm{HC}_{2} \mathrm{O}_{4}\right)_{3}\right)$ with oxalate, which displayed a negative effect on the reduction process. The high reaction temperature and high acidic medium could destroy the stable structure of a complex compound to release oxalate, and facilitate the reduction of $\mathrm{Cr}(\mathrm{VI})$.

Author Contributions: Conceptualization, H. Peng; Formal analy sis, L.Lv; Funding acquisition, H. Peng; Investigation, B. Yuan; Methodology, H. Peng; Project administration, Hao Peng; Software, J. Guo; Supervision, Hao Peng; Validation, H. Huang, B. Li; Writing - original draft, H. Peng; Writing - review \& editing, H. Peng.

Funding: This work was supported by the Science and Technology Research Program of Chongqing Municipal Education Commission (No. KJQN201901403), the Chongqing Science and Technology Commission (No. cstc2018jcyjAX0018).

Conflicts of Interest: The authors declare no conflict of interest.

\section{References}

1. J. Song, H. Kong, J. Jang, Adsorption of heavy metal ions from aqueous solution by poly rhodanine-encapsulated magnetic nanoparticles, J Colloid Interf Sci, 359 (2011) 505-511.

2. G.Z. Kyzas, K.A. Matis, Nanoadsorbents for pollutants removal: A review, Journal of Molecular Liquids, 203 (2015) $159-168$.

3. V. Nogueira, I. Lopes, T. Rocha-Santos, F. Gonçalves, R. Pereira, Toxicity of solid residues resulting from wastewater treatment with nanomaterials, Aquat Toxicol, 165 (2015) 172-178.

4. N. Adhoum, L. Monser, N. Bellakhal, J.-E. Belgaied, Treatment of electroplating wastewater containing Cu2+, $\mathrm{Zn} 2+$ and $\mathrm{Cr}(\mathrm{VI})$ by electrocoagulation, Journal of hazardous materials, 112 (2004) 207-213.

5. M. Hunsom, K. Pruksathorn, S. Damronglerd, H. Vergnes, P. Duverneuil, Electrochemical treatment of heavy metals $(\mathrm{Cu} 2+, \mathrm{Cr} 6+, \mathrm{Ni2}+)$ from industrial effluent and modeling of copper reduction, Water research, 39 (2005) 610-616.

6. A. Azimi, A. Azari, M. Rezakazemi, M. Ansarpour, Removal of Heavy Metals from Industrial Wastewaters: A Review, ChemBioEng Reviews, 4 (2017) 37-59.

7. H. Xin, Q. Xinhong, C. Jinyi, Preparation of Fe(II)-Al layered double hydroxides: Application to the adsorption/reduction of chromium, Colloids and Surfaces A: Physicochemical and Engineering Aspects, 516(2017) 362-374.

8. R. Fu, X. Zhang, Z. Xu, X. Guo, D. Bi, W. Zhang, Fast and highly efficient removal of chromium (VI) using humus supported nanoscale zero-valent iron: Influencing factors, kinetics and mechanism, Sep Purif Technol, 174 (2017) 362-371.

9. Y. Zhao, Removal of Chromium Using Electrochemical Approaches: A Review, Int J Electrochem Sc, (2018) 12501259.

10. H. Peng, Y. Leng, J. Guo, Electrochemical Removal of Chromium (VI) from Wastewater, Applied Sciences, 9 (2019) 1156. 
11. H. Peng, Y. Leng, Q. Cheng, Q. Shang, J. Shu, J. Guo, Efficient Removal of Hexavalent Chromium from Wastewater with Electro-Reduction, Processes, 7 (2019) 41.

12. Z.Zhao, a. He, J. Lin, M.Feng, V. Murugadoss, T. Ding, H. Liu, Q. Shao, X. Mai, N. Wang, H. Gu, S. Angaiah, Z. Guo, Progress on the Photocataly tic Reduction Removal of Chromium Contamination, Chem Rec, 19 (2019) 873882.

13. X. Zheng, F. Kang, X. Liu, H. Peng, Z. JinYang, Carbon-coated Mg-Al layered double oxide nanosheets with enhanced removal of hexavalent chromium, J Ind Eng Chem, 80 (2019) 53-64.

14. H. Peng, J. Guo, B. Li, Z. Liu, C. Tao, High-efficient recovery of chromium (VI) with lead sulfate, Journal of the Taiwan Institute of Chemical Engineers, 85 (2018) 149-154.

15. S. Studenroth, S.G. Huber, K. Kotte, H.F. Scholer, Natural abiotic formation of oxalic acid in soils: results from aromatic model compounds and soil samples, Environ Sci Technol, 47 (2013) 1323-1329.

16. J. Sun, J.D. Mao, H. Gong, Y. Lan, Fe(III) photocataly tic reduction of Cr(VI) by low-molecular-weight organic acids with alpha-OH, J Hazard Mater, 168 (2009) 1569-1574.

17. C. Zhang, X.Li, X. Bian, T. Zheng, C. Wang, Poly acrylonitrile/manganese acetate composite nanofibers and their cataly sis performance on chromium (VI) reduction by oxalic acid, J Hazard Mater, 229-230 (2012) 439-445.

18. Y. Mu, X. Jiang, Z. Ai, F. Jia, L. Zhang, Mn2+ promoted Cr(VI) reduction with oxalic acid: The indispensable role of In-situ generated Mn3+, Journal of Hazardous Materials, 343 (2018) 356-363.

19. B. Deng, A.T. Stone, Surface-Catalyzed Chromium(VI) Reduction_Reactivity Comparisons of Different Organic Reductants and Different Oxide Surfaces, Environmental Science \& Technology, 30 (1996) 2484-2494.

20. B. Jiang, X. Wang, P. Hu, M. Wu, J. Zheng, W. Wu, Dual enhancement-inhibition roles of poly carboxy lates in $\mathrm{Cr}(\mathrm{VI})$ reduction and organic pollutant oxidation in electrical plasma system, Chemosphere, 144 (2016) 1611-1617.

21. H. Peng, J. Guo, Z. Liu, C. Tao, Direct advanced oxidation process for chromium(III) with sulfate free radicals, SN Applied Sciences, 1 (2019) 14.

22. H. Peng, Q. Shang, R. Chen, Y. Leng, J. Guo, Z. Liu, C. Tao, Oxidative Leaching Kinetics of Vanadium from the Vanadium-Chromium-Reducing Residue with K2Cr2O7, ACS Omega, 5 (2020) 8777-8783.

23. H. Peng, L. Yang, Y. Chen, J. Guo, Oxidative Leaching of Vanadium from Vanadium-chromium Reducing Residue with MnO2, IOP Conference Series: Materials Science and Engineering, 730 (2020) 012041.

24. H. Peng, L. Yang, Y. Chen, J. Guo, B. Li, Recovery and Separation of Vanadium and Chromium by Two-Step Alkaline Leaching Enhanced with Electric Field and H2O2, ACS Omega, (2020) 5340-5345.

25. V.A. Okello, S. Mwilu, N. Noah, A. Zhou, J. Chong, M.T. Knipfing, D. Doetschman, O.A. Sadik, Reduction of hexavalent chromium using naturally-derived flavonoids, Environmental Science and Technology, 46 (2014) 1074310751.

26. X. Zhang, W. Fu, Y. Yin, Z. Chen, R. Qiu, M.-O. Simonnot, X. Wang, Adsorption-reduction removal of Cr(VI) by tobacco petiole pyrolytic biochar: Batch experiment, kinetic and mechanism studies, Bioresour Technol, 268 (2018) 149-157.

27. G. Chen, J. Han, Y. Mu, H. Yu, L. Qin, Two-stage chromium isotope fractionation during microbial Cr(VI) reduction, Water Research, 148 (2019) 10-18. 